\title{
A Method of Medial Tarsorraphy for Correction of Lagophthalmos and Ectropion
}

\author{
A. GRAGE WARREN, м.B., B.s., D.T.м. \& H. (syd.) \\ Medical Superintendent, Hay Ling Chau Leprosarium, Hong Kong
}

In recent years the operation of 'Temporalis Musculo-fascial Sling' has become the operation of choice in many patients with lagophthalmos. The older operation of 'tarsorraphy' still has its place in the protection of the eye in older patients, and in patients where temporary protection is needed until recovery occurs or more extensive surgery can be done.

It has been stated that a closure of at least one third of the fissure is necessary for an effective result but this frequently results in an unsightly appearance and hence many patients refuse lateral tarsorraphy. Also ectropion of the lower lid may occur especially at the inner end causing watering. A combination of lateral and medial tarsorraphy is frequently more cosmetically and more functionally effective than a lateral tarsorraphy alone.

Various modifications of operations recommended for ectropion and lagophthalmos have been tried and found unsatisfactory. Basically I feel that this is because little attention has been

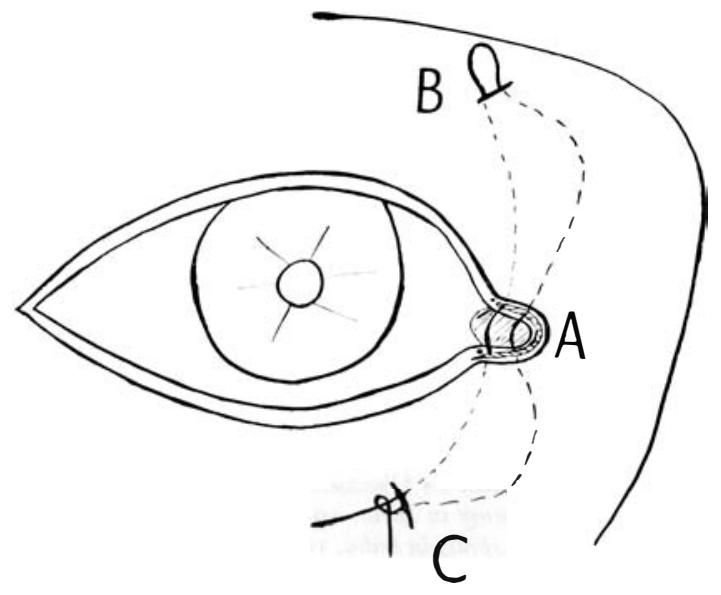

FIG. I

Diagram of the Suture route. paid to the basic anatomical defect. It will be noticed that when a normal eye is tightly closed the skin of the forehead and cheek is pulled inwards towards the medial angle of the eye. This is the normal function of the obicularis occuli muscle that is not functioning in lagophthalmos, and hence a sagging of the skin away from the medial angle of the eye results. In an attempt to correct this defect the following operation was devised and has been found effective over a period of four years.

\section{Method}

(a) The medial epicanthal skin is prepared as for a routine tarsorraphy. The incision extends along the grey line from the level of the upper punctum to the lateral side of the lower punctum. If the incision is kept to a depth of $\mathrm{I} \mathrm{mm}$. and on the outer edge of the lid there is little danger of damage to the lacrymal apparatus whose position can be checked by the passage of a probe. The incision is deepened by blunt dissection to make a raw surface about $2 \mathrm{~mm}$. wide.

(b) An incision is made, about $2 \mathrm{~mm}$. long, slightly lateral to the upper punctum and just below the orbital margin.

(c) An incision is made, $2 \mathrm{~mm}$. long, about $\mathrm{I} \mathrm{cm}$. lateral to and $\mathrm{I} \cdot 5 \mathrm{~cm}$. below the lower punctum, and deepened slightly.

(d) A length of monofilament nylon (No 6xo) is passed from $(\mathrm{C})$ to the lower half of $(\mathrm{A})$ near the punctum. It passes across the caruncle and into the upper edge by the punctum and out at (B). Here the direction is reversed so that the needle enters at (B), biting deeply to catch the fascia around the orbit and to take a different path back to the upper border of (A), more medial than the point of entry, then across the caruncle and by a different route to $(\mathrm{C})$. 
(e) One or two small black cotton sutures are used to ensure eversion of the skin edges of $\mathrm{A}$. (Remove in 3 days.)

$(f)$ The nylon is then pulled sufficiently tight to slightly over-correct the defect. It will be noticed that the skin is pulled in towards the medial angle of the eye. It will also be realised that the lower lid can be shortened relatively to the upper lid by careful selection of the sites where the nylon passes across the caruncle. The

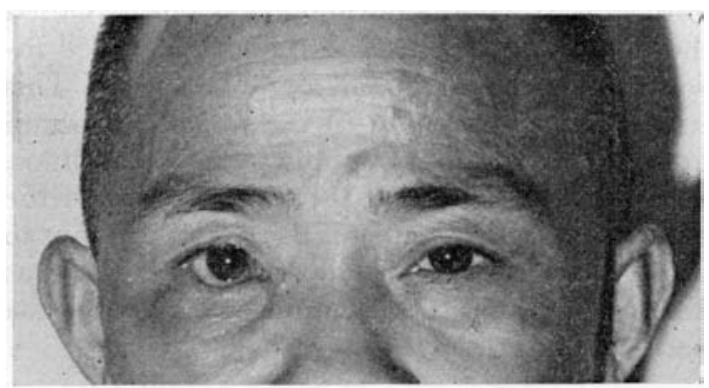

FIG. 2. Patient with Lagophthalmos on admission.

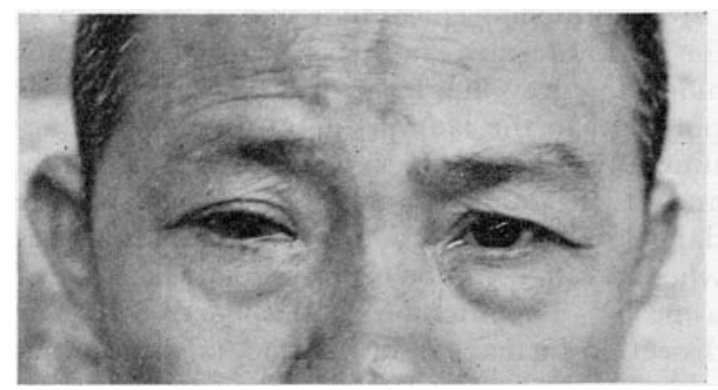

FIG. 3. Same patient after Medical Tarsorraphy with eyes open.

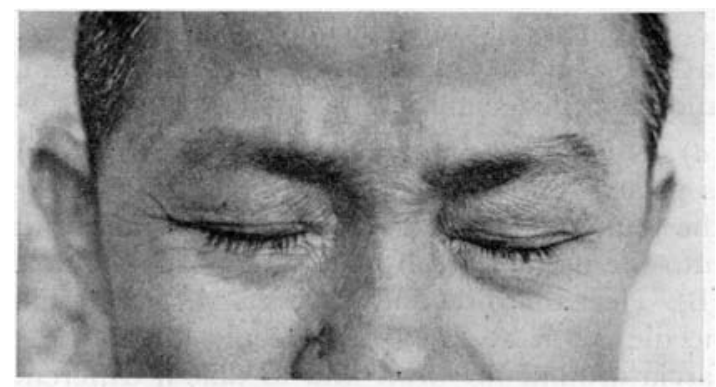

FIG. 4. Same patient after Medical Tarsorraphy with eyes_shut. nylon is knotted at least three times to prevent slipping and cut short. It is usually possible to bury the ends without suturing the incision $\mathrm{C}$.

( $g$ ) The minimum of dry dressings may be applied but it is frequently not necessary.

This procedure has been used on over 25 patients; some previously failed by other methods. The first patient was in December I 960 and is still functional with the nylon in situ. It has caused no trouble though previously he had had several types of closure that had produced inadequate results.

This method generally gives better functional and cosmetic results than more conventional procedures. The patency of the lacrymal apparatus has been checked on a number of cases after surgery and found patent. Many patients claim marked relief from watering which is often the original complaint; this is easily explained as the lower punctum is brought into better apposition with the eyeball.

Failure has occurred but is is usually due to insufficient tension in tying the nylon.

\section{Summary}

A method of medial tarsorraphy using a buried nylon suture is described. The suture does not have to be removed and so provides a more permanent as well as a more cosmetically acceptable answer to the problem of lagophthalmos than many other methods.

\section{A GKNOWLEDGEMENTS}

I am very grateful to Dr Margaret Brand for her careful tuition in the care of the eyes of leprosy patients and for her encouragement and assistance in the production of this article.

\section{REFERENGES}

cochrane, R. G., 'Leprosy in Theory and Practice',

Chapter on Reconstructive Surgery of the Face. GRAY Anatomy Descriptive and applied. BERENS, The Eye and its Diseases. FRITSCHI, E. P. Leprosy in India, I958, Jan. p. 83. SOMMerset et al., Leprosy in India, i 96o, Apr., p. i 6. Antia, N. H., Leprosy in India, 1960, Apr., p. I 12. ANTIA, N. H., Leprosy in India, 1964, Oct., p. 269. 